intelectual", y concluye con el siguiente juicio: "Sin duda, [es] un maestro que dejó profundas huellas en el país que lo cobijó, y con proyecciones a gran parte de Latinoamérica”.

La valorización de su legado es el mejor homenaje que podemos hacer a su memoria.

Luis Merino Montero Departamento de Música Facultad de Artes

Universidad de Chile lmerino@uchile.cl

\title{
Graciela Paraskevaídis
}

(Buenos Aires, 1 de abril, 1940 - Montevideo, 21 de noviembre, 2016) ${ }^{1}$

Es muy difícil referirme en pocas palabras a mi querida amiga Graciela, ya que pasa el tiempo, estoy impactado por su partida, y no he dejado de recordar nuestros encuentros "aquí y allá, en este y en otro continente", siempre reconfortantes, generosos de su parte y además muy educativos.

Graciela estudió en el Conservatorio Nacional de Música de Buenos Aires y los completó en el Centro Latinoamericano de Altos Estudios Musicales del Instituto Torcuato Di Tella en dicha ciudad. Posteriormente estuvo en Freiburg, Alemania, como becaria del DAAD (Servicio Alemán de Intercambio Académico). Recibió enseñanzas y estímulos para la composición de Roberto García Morillo, Iannis Xenakis y Gerardo Gandini.

Se sentía deudora de los ejemplos de ética de Edgar Varèse, Silvestre Revueltas y Luigi Nono. Residió en 1984 en Berlín, como invitada del Programa de Artistas en Residencia y en 1998 en Stuttgart como invitada de la Akademie Schloss Solitude. Recibió diversos premios discernidos por la Asociación Argentina de Compositores, la Municipalidad de Buenos Aires, y la Academia de Artes de Berlín, entre otras instituciones.

En 1994 el Instituto Goethe de Múnich le otorgó la Medalla Goethe. En 2006 recibió el Premio Morosoli en Uruguay. Integró el Núcleo Música Nueva de Montevideo y la Sociedad Uruguaya de Música Contemporánea, además de formar parte del colectivo de organización de los Cursos Latinoamericanos de Música Contemporánea.

Como muchos colegas de mi generación la conocí personalmente en los CLAMC (Cursos latinoamericanos de música contemporánea), los que lideró junto con su leal compañero Coriún Aharonián. Estos nómades cursos contribuyeron a despertar la conciencia musical, política, filosófica, psicológica de tantas personas y los ayudaron a conocer mejor este mundo. En ellos nacieron también grandes amistades.

Tuve la oportunidad de ser invitado por primera vez en 1986, cuando estos cursos se realizaron en Cerro del Toro, Uruguay. Pude contar entonces a mis hermanos de este continente lo que sucedía en nuestro país durante la dictadura, y transmitir a Chile las noticias de nuestros colegas músicos, puesto que estábamos bastante enclaustrados a causa de la censura operante. Luego volví a los CLAMC realizados en la localidad de Mendes en el Estado de Rio de Janeiro, Brasil.

De ahí en adelante, nuestra amistad con Graciela no cesó hasta que la naturaleza hizo su parte y se la llevó. Dejó un vacío fundamental, pues poseía un gran espíritu que era crítico pero constructivo junto con la capacidad de "ver" en profundidad los acontecimientos del planeta.

Como docente, Graciela realizó una extensa actividad privada y, entre 1985 y 1992, se desempeñó en la Escuela Universitaria de Música en Montevideo. Dictó seminarios y conferencias en diversos países, e integró jurados de concursos nacionales e internacionales de composición.

Escribió numerosos ensayos sobre música latinoamericana contemporánea y fue colaboradora regular de las revistas Pauta, Revista Musical Chilena y MusikTexte además del diccionario Komponisten

1 Los agradecimientos a Coriún Aharonián por proporcionar los datos curriculares actualizados. 
der Gegenwart. Entre 1990 y 2000 fue coeditora de la World New Music Magazine, anuario de la Sociedad Internacional de Música Contemporánea; y desde 2004 del sitio www.latinoamerica-musica.net, dedicado a la difusión de textos de y sobre música latinoamericana actual.

Es autora de los libros La obra sinfónica de Eduardo Fabini (1992) y Luis Campodónico, compositor (2000). Tradujo del alemán numerosos artículos y el libro Los signos de Schoenberg, de Jean-Jacques Dünki (Caracas: Monte Ávila 2005).

Las amistades no tienen que ver con pertenecer a una misma generación, lo que comprobé con mi maestro Cirilo Vila y con Graciela, con quien teníamos casi veinte años de diferencia. Lo mínimo que pude hacer por ella en mi rol de educador y director fue enseñar su música tanto en las aulas como dirigiendo sus obras de cámara en conciertos.

Sus composiciones se han interpretado en Alemania, Argentina, Bolivia, Brasil, Canadá, Chile, Colombia, Corea del Sur, Cuba, Escocia, España, Estados Unidos de Norteamérica, Francia, Gran Bretaña, Grecia, México, Rumania, Suecia, Suiza, Turquía, Uruguay y Venezuela. Parte de su producción fue incluida en fonogramas diversos editados en Alemania, Bolivia, Brasil y Uruguay. Tres de ellos son monográficos y aparecieron bajo el sello Tacuabé de Montevideo: Magma (1996), Libres en el sonido (2003) y Contra la olvidación (2012).

Desde su juventud Graciela Paraskevaídis tuvo grandes amistades en Chile. en las que se mezcló la política y la música. A su generación le tocó vivir episodios fuertes e impactantes de golpes militares que impusieron la brutalidad por las armas. Cada vez que venía a Chile su agenda estaba completa. Cultivó grandes amistades en la gran mayoría de los otros países de América Latina, en los que su figura creativa no era para nadie indiferente como tampoco lo fue su generosidad.

En el 2014 el sello Iberoamericana-Vervuert (Frankfurt-Madrid) publicó el libro Sonidos y hombres libres. Música nueva de América Latina en los siglos XX y XXI (En honor a Coriún Aharonián y Graciela Paraskevaídis) compilado por Hanns-Werner Heister y Ulrike Mühlschlegel. El mismo año 2014 la editorial Gourmet Musical (Buenos Aires) publicó Estudios sobre la obra musical de Graciela Paraskevaídis compilado por Omar Corrado. En 2015 el cineasta Ricardo Casas dio a conocer Libres en el sonido, un largometraje documental acerca de su vida y obra.

Si la libertad existe, independientemente de lo que cada uno piensa de ella, Graciela por cierto que sí la propiciaba. Si el cielo existe, estará habitado eternamente por esta inigualable mujer. Ella legó a todos quienes la conocimos la enseñanza de la fraternidad, y la creación a ultranza, junto con la intransigencia en practicar los principios de dignidad, ética y humanidad.

\author{
Eduardo Cáceres Romero \\ Facultad de Artes, Departamento de Música, \\ Universidad de Chile, Chile \\ kazeres@gmail.com
}

\title{
Lothar Siemens Hernández \\ (Las Palmas, Gran Canaria, España, 16 de agosto, 1941 - 28 de febrero, 2017)
}

La personalidad de Lothar Georg Siemens Hernández fue polifacética como la de un incontestable humanista de los tiempos modernos, intelectual de altos vuelos. A lo largo de su fecunda vida ejerció con extraordinario rigor actividades muy diversas: la de empresario, promotor cultural y, por encima de todo, la de musicólogo y compositor. En su propia familia encontró el caldo de cultivo de su dedicación vital: de su padre Lothar heredó el nervio empresarial; de sus antepasados Gregorio Millares Cordero y Agustín Millares Torres, el rigor intelectual y el amor a los libros y a las artes; y de su tía Lola de la Torre Champsaur, profesora suya en la adolescencia, la pasión por la música.

Desde muy joven pudo materializar de manera simultánea su dedicación a la música con su trabajo directivo en la empresa familiar "Siemens Maquinaria S. A.". Entre 1996-2004 fue presidente, en largos períodos, del Círculo de Empresarios de Gran Canaria. Y a partir de 2005 ha sido Presidente de Administración del Consejo Social de la Universidad de Las Palmas de Gran Canaria. 